\title{
DWARVES AND FLAMINGOES
}

Foreign rain. Foreign currency.

Foreign depression.

At last the clouds part

And the day is green as green marble,

Streaked by silk

And the whites of eyes.

At the ruins, sitting between

The marble sandals and marble hands

Of an accident prone god

You watch the wind blow water

From a puddle on the stone

Forehead into a stone eye,

Illustrating the Entropy Law of Tears:

Increasing, cumulative in time,

Flowing from present to past.

(The First Law, the Conservation

Of Tears, is Beckett's: “The tears

Of the world are a constant quantity.

For each one who begins to weep

Somewhere another stops.")

Then a woman walks by with four cameras

And two light meters

Hung around her breasts:

$$
\text { a Kodak Artemis }
$$

To be worshipped from any angle.

You stop patching memories

And digging at unconscious foundations

And leap down

To follow her through the winding streets.

Every wall and turn is her background 
For her. You watch her back

And shoulders rotate above her hips,

Her hips above her legs,

Find a pattern even

To her sandaled feet slipping

On wet cobblestones.

You lose her at a light

But go on. A corner unfolds

Like butterfly wings. You wind

Your camera. You look around.

The strangers have gone to a foreign

Land, but left their bodies

As maps. You cock the shutter,

Take a reading.

You join them now:

The flamingoes that do not watch themselves Being photographed on one leg,

The dwarves that do,

Smiling or scowling,

On almost two. 